\title{
La auto-toma de la prueba de HPV ofrecida por agentes de salud cuadruplica el tamizaje del cáncer cervicouterino
}

The self-collection of HPV DNA testing offered by community health workers quadruples the cervical cancer screening

\section{Objetivos}

Evaluar si la auto-toma de la prueba de virus del papiloma humano (sigla en inglés, HPV) logra incrementar la cobertura del tamizaje.

\section{Diseño y lugar}

Ensayo clínico aleatorizado en conglomerados ("cluster") de base poblacional (estudio EMA) realizado en Jujuy, Argentina, del 1/7/2012 al 31/12/2012.

\section{Pacientes e intervención}

Se incluyeron mujeres mayores de 30 años visitadas por agentes sanitarios provinciales. Se excluyeron mujeres con prueba de HPV realizada en el último año, histerectomizadas, embarazadas, incapaces o con antecedentes de patología en el cuello uterino. Las pacientes fueron aleatorizadas a un grupo control, siendo invitadas a asistir a los centros de salud donde un profesional les tomaría de forma gratuita la prueba de HPV, o al

Figura 1. Diagrama de flujo de pacientes
Arrosi y col. Lancet Glob Health 2015;3:85-94.

grupo intervención, en cuyo caso podían elegir entre tomar ellas mismas la muestra o asistir al centro de salud.

\section{Medición de resultados principales}

El resultado primario fue el número de mujeres que realizaron la prueba de HPV dentro de los seis meses posteriores a la visita inicial. El análisis fue por intención de tratar. En forma secundaria se evaluó la aceptabilidad de la auto-toma, la positividad de la prueba, el diagnostico de $\mathrm{CIN} 2+y$ el tratamiento en cada grupo hasta el 31/12/2013.

\section{Resultados}

Participaron 191 agentes sanitarios que visitaron a $7.650 \mathrm{mu}-$ jeres: 1.379 fueron excluidas, más del $95 \%$ aceptó participar. Se incluyeron 3.049 mujeres en el grupo intervención (86\% acepto realizarse la auto-toma) y 2.964 en el grupo control (ver figura 1). Del total de mujeres incluidas, $71 \%$ no tenían tamizaje realizado en los cuatro años previos.

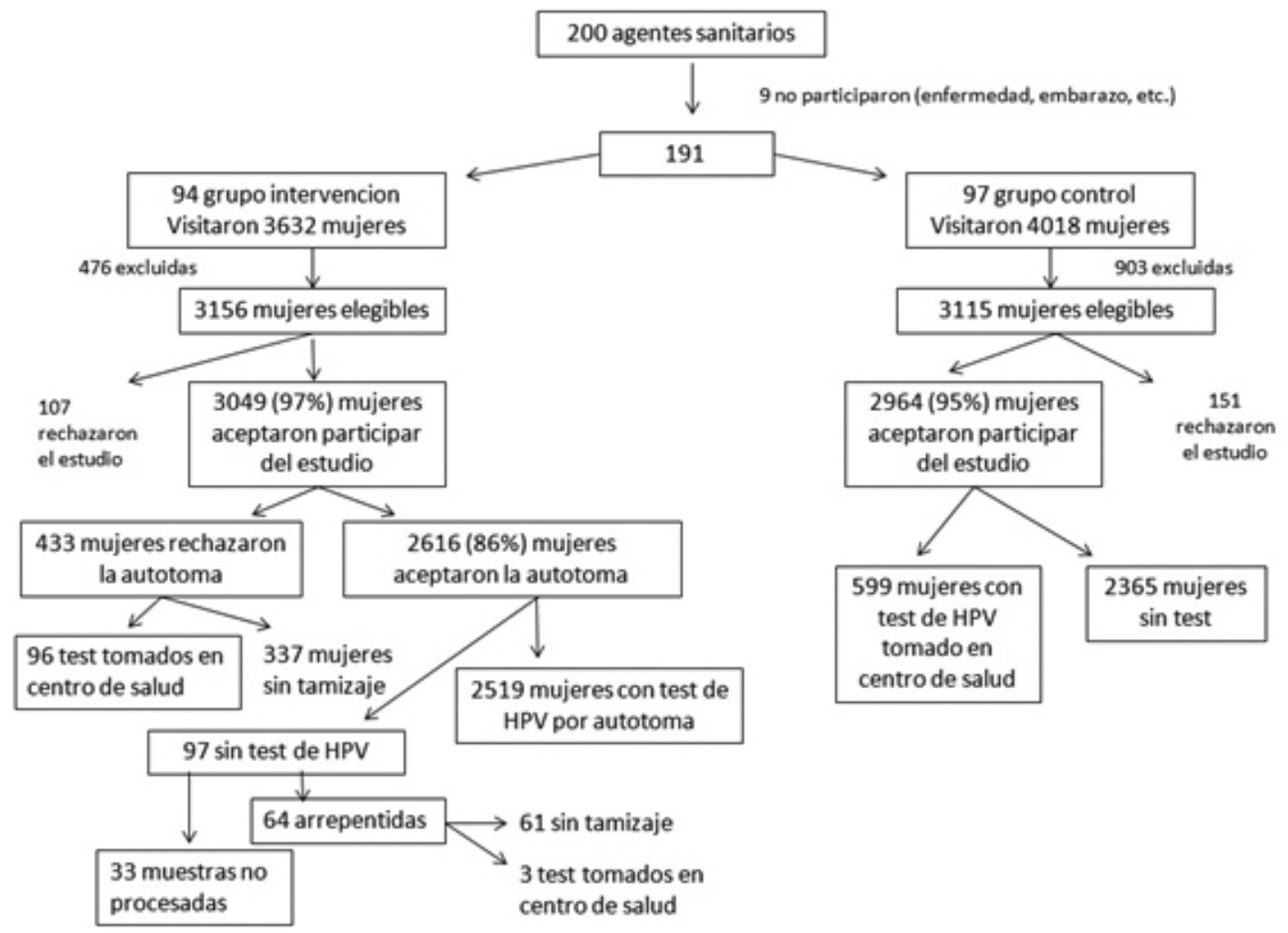

El $86 \%$ de las mujeres del grupo intervención tuvo una prueba de HPV realizada en los seis meses posteriores a la visita del agente sanitario (96\% por auto-toma) comparado con el $20 \%$ del grupo control (ver tabla 1).
La aceptabilidad de la auto-toma fue del $96 \%$, la cual no fue influenciada por el sexo del agente sanitario ni por el ámbito rural o urbano. El 1,3\% de muestras de auto-toma no se analizó.

Tabla 1. Número de mujeres que realizaron la prueba de HPV dentro de los seis meses posteriores a la visita inicial.

\begin{tabular}{l|c|c|c}
\multicolumn{1}{c|}{ Mujeres } & Grupo intervención & Grupo control & RR (IC95\%) \\
\hline Todas & $2.618 / 3.049(86 \%)$ & $599 / 2.964(20 \%)$ & $4,02(3,44$ a 4,71) \\
\hline Sin Pap en los últimos cuatro años & $1.874 / 2.160(87 \%)$ & $336 / 2126(16 \%)$ & $4,98(4,12$ a 6,02) \\
\hline Con Pap en los últimos cuatro años & $771 / 889(87 \%)$ & $336 / 838(40 \%)$ & $2,76(2,39$ a 3,20) \\
\hline
\end{tabular}

RR: riesgo relativo. IC 95\%: intervalo de confianza del 95\%. Pap: Papanicolau. 


\section{Conclusión}

La auto-toma de la prueba del VPH es una estrategia efectiva: cuadriplicó la cobertura con pocos inconvenientes logísticos y puede ser ofrecida por hombres. A pesar de no tener contacto inicial con un profesional, el $88 \%$ de las mujeres con resultados positivos para la prueba realizó colposcopia y el $85 \%$ recibió tratamiento comparado con un $70 \%$ de tratamientos mediante tamizaje con Papanicolaou (Pap). La tasa de detección de CIN 2+ fue in- ferior cuando la prueba fue realizada mediante autotoma versus toma por profesional, pero el aumento en la cobertura permitió detectar cinco veces más casos de $\mathrm{CIN} 2+$.

Existen barreras en el acceso a la salud que no son sorteadas con la consejería ni con la disponibilidad gratuita de los métodos de rastreo. Los cambios tecnológicos deben asociarse a innovaciones sociales para que su implementación sea exitosa.

\section{Comentario}

Este estudio evaluó el desempeño de la modalidad auto-toma de la prueba de HPV en un contexto real, analizando aceptabilidad, cobertura, referencia a centros de diagnóstico y acceso al tratamiento. Si bien la tasa de detección de CIN 2+ es menor cuando la propia mujer es quien toma la muestra, la modalidad auto-toma permitió aumentar cuatro veces la cobertura y así diagnosticar cinco veces más lesiones precursoras respecto del tamizaje en centros asistenciales.

En el contexto de nuestro país la auto-toma aumentaría la derivación a colposcopia ya que no cuenta con la posibilidad de realizar el "triage" mediante citología que se hace cuando la prueba de VPH es tomada por un profesional (en este caso se hace toma conjunta, se leen los Paps de las mujeres HPV+ y se derivan solamente mujeres HPV+ con alteraciones citológicas). Este estudio nos muestra que las innovaciones tecnológicas por si solas no son efectivas si no se acompañan de cambios estratégicos.

\section{Conclusiones del comentador}

Existen barreras en el acceso al tamizaje en centros de salud que no son superadas con la consejería específica. El rol del agente sanitario es fundamental para el éxito de la modalidad auto-toma y debe coordinarse con otros puntos clave como el transporte de muestras y referencia de las mujeres a diagnostico y tratamiento.

María Florencia Marcos [ Servicio de Ginecología del Hospital Italiano de Buenos Aires florencia.marcos@hospitalitaliano.org.ar ]

Marcos MF. La auto-toma de la prueba de HPV ofrecida por agentes de salud cuadruplica el tamizaje del cáncer cervicouterino. Evid Act Pract Ambul. 2017;20(2):51-52. Comentado de: Arrossi S, y col. Effect of self-collection of HPV DNA offered by community health workers at home visits on uptake of screening for cervical cancer (the EMA study): a population-based cluster-randomised trial. Lancet Glob Health. 2015;3(2):e85-94. PMID: 25617202.

\section{Referencias}

1. Winer RL, y col. Assessing Acceptability of Self-Sampling Kits, Prevalence, and Risk Factors for Human Papillomavirus Infection in American Indian Women. J Community Health. 2016 Apr 5. [Epub ahead of print] PubMed PMID: 27048284.

2. Smith M, y col. Impact of HPV sample self-collection for underscreened women in the renewed Cervical Screening Program. Med J Aust. 2016 Mar 21;204(5):194.

3. Racey CS, y col. Self-collected HPV testing improves participation in cervical cancer screening: a systematic review and meta-analysis. Can J Public Health. 2013 Feb 11;104(2):e159-66.

4. Zhao FH, y col. Pooled analysis of a self-sampling HPV DNA Test as a cervical cancer primary screening method. J Natl Cancer Inst. 2012 Feb 8:104(3):178-88.

5. Arbyn M, y col. Accuracy of human papillomavirus testing on self-collected versus clinician-collected samples: a meta-analysis. Lancet Oncol. 2014 Feb;15(2):172-83.

6. Snijders PJ, y col. High-risk HPV testing on self-sampled versus clinician-collected specimens: a review on the clinical accuracy and impact on population attendance in cervical cancer screening. Int J Cancer. 2013 May 15;132(10):2223-36. 